\title{
Science and politics: From science to decision making
}

Science and risk assessment are important features of health and environmental legislation in most, if not all, nations. The technique of science-based risk assessment is designed to provide a rational mechanism for distilling and evaluating scientific knowledge regarding the risks of exposure to hazardous chemicals on human health or the environment. The outcome of science-based risk assessments informs policy makers, when deciding on risk management measures, on how to reduce identified risks to levels acceptable to broader society (Stern and Fineberg, 1996).

Structures of risk regulation, based on risk assessment and risk management, have been widely adopted in national legal systems as well as in the trans-national regulatory processes of the European Union (e.g., European Commission, 2000). In recent times, scientific risk assessment has also begun to appear in international legal regimes concerned with health and environmental regulations (e.g., The Stockholm Convention on Persistent Organic Pollutants (POPs) (UNEP, 2001)). The most prominent example of this trend is in the area of international trade law, where the Sanitary and Phytosanitary Measures Agreement (SPS Agreement) of the World Trade Organisation prescribes scientific risk assessment as a basis for measures dealing with risks to human, animal, and plant life or health (WTO, 1995).

Despite this anchorage of the use of science in regulations, particularly in Europe, environmental regulation has become one of the most contentious issues in the public policy arena. From genetically modified food, nuclear power to the regulation of dangerous chemicals, society's debates about the interplay between technology and risk have become increasingly bitter. In this dispute, the role of the individual scientist or technologist has become, in its turn, ever more contentious. For toxicologists, and a variety of other experts drawn up into this process, this is all proving to be rather puzzling. They find themselves increasingly asked to adjudicate in technical language on issues which are actually about political principles.

What has led to this situation? Löfstedt (2004) identified two phases in the development of European regulation. In the first phase, which he described as the old model of 'con- sensual style' and which was put in place as early as 1842 , regulatory decisions were taken behind closed doors by a number of elite groups including heads of industry, senior regulators, and representatives from trade unions. In this system, scientists had an important role to play in outlining the "pros and cons" of regulatory action. This consensual model ensured sufficient credibility of regulators in Europe. Not only was there little need for separating risk assessment from risk management, but only a very small minority of the population felt that a close collaboration between regulators and industry was a negative thing.

The situation in Europe changed dramatically in the early to mid 1990s. A result of a number of regulatory scandals such as the tainted blood scandal in France, the BSE crisis and the Belgium dioxin crisis, paired with an amplification of risk by the media, public trust towards regulators, industry and science in general, eroded significantly (Löfstedt and Vogel, 2001). Today, scientific results are increasingly questioned by the media, stakeholders and 'other' scientists claiming contrary evidence (O'Brien, 2000). Moreover, philosophers of science deny the view that risk assessment and, more generally science, is value free. It is argued that the nature of risk assessment, with its inherent uncertainties, makes values even more influential in risk assessment than in pure science (Wandall, 2004).

As the level of public trust toward regulators and policy makers has declined, researchers have concluded that the consensual model of regulatory decision making in Europe does not exist anymore (Majone and Everson, 2001). A new model of regulatory decision making, which Löfstedt described as 'participatory-transparent.' has emerged. The main features of this model are (Löfstedt, 2004):

- Greater public and stakeholder participation;

- Greater use of precaution (and the formalisation of the precautionary principle at EU level);

- Greater consideration for environmental and social values;

- Greater transparency in regulatory strategies and decisions; and

- Greater focus on regulatory impact analysis. 
In the new EU model of regulatory decision making, science has received a different role. Scientists do not play the prominent role that they once did. Science is taken into consideration in the process, but in the eyes of public, scientists are just another stakeholder. Contrary to this general trend, the recently released draft guideline for environmental risk assessment of pharmaceuticals (EMEA, 2005) distinctly embraces the involvement of experts. However, in clear contrast to other previous and some present guideline documents (Dietrich et al., 2005), the EMEA draft guideline provides details as to what defines an expert and how the expertise should be identified. The latter can be seen as an overt effort to instill more confidence of the stakeholders as well as the public in the risk assessment process. Moreover, it aims to move the "expert" back into the presumably unbiased position of the consulting scientist having a weight of evidence approach. In the same lines, but at a more general level, the European Policy Centre analysed the role of science in the decision-making of the European Union and made a number of recommendations on how to the improve the use of science by EU institutions (EPC, 2005).

This special issue of Regulatory Toxicology and Pharmacology examines, predominantly on the basis of EU case studies, how science is or ought to be used in a regulatory context and in the public debate. The nine papers presented in this special issue reflect the views and studies from academic, regulatory, NGO, and industry scientists. Six of the papers were presented at two Special Symposia on 'Science and Politics: From Science to Decision Making' for the occasion of the SETAC Europe Annual Meeting in Prague (May 2004) and in Lille (May 2005). Two further papers (Rudén and Hansson; Ballantine and Devonald) were supplemented to contribute to the discussion on the newly proposed European chemicals legislation 'REACH' and 'Regulatory Impact Assessment' as a tool to stimulate the development of better regulations.

The first contribution from Allio et al. provides an overview of the issues related to the use of science in the EU decision making process. This research, which was conducted by the risk forum of the European Policy Centre, aimed at examining the risk analysis process at the EU level, identifying options to enhance the role of science in the EU decision making process and promoting improved communications between scientists, policy makers, stakeholders, and citizens.

Following this 'introduction,' a first block of three papers addresses issues related to existing EU chemicals legislation and the European Commission's proposal for a new chemicals legislation in Europe, widely known as 'REACH.' Rudén examines the principles of existing EU process for risk assessments as defined by the legislations and official guidelines and the actual workings of the system on the basis of two case studies. Petry and Meads review the proposed REACH legislation and focus their analysis on some science-based issues related to the architecture and provisions which, without further clarifications and improvements, could lead to unintended consequences for businesses. In the third paper, Rudén and Hanssen examine whether the proposed REACH legislation will lead to a better scientific basis for risk assessment and provide recommendations for improvements to simplify the proposed risk assessment procedures.

In the next block of two papers dealing with aspects 'beyond science' that play a role in environmental policy making, Tencalla discusses on the basis of experiences made with the introduction of crop biotechnology in Europe important factors leading to acceptance or rejection of new technologies in Europe. Using past learnings with hazardous chemicals and the more recent discussions on the risks related to genetically modified organisms, Karlsson discusses the role of science and norms in risk assessment and risk management, giving specific consideration to the precautionary principle, stakeholder participation, and the polluter pays principle in the context of sustainable development.

The last block of this special issue, deals with Regulatory Impact Analysis (RIA) as a tool and technique to evaluate and improve the quality of the regulatory process and the consideration of science in an international trade context. Ballantine and Devonald describe and evaluate the new approach of the RIA process adopted by the European Commission, in theory and practice, and make a number of recommendations for further improvements to the quality of the regulatory process in the European Union. Barnett contends that the classical approach to RIA, based on compliance costs, is inappropriate to fully understand the aggregate impact of legislation. The final paper by Lugard provides some legal views on the use of science in International Trade Law. Lugard argues that science and risk assessment is anchored in WTO agreements and nonscience based regulations that affect trade without proper scientific justification, can be legally challenged.

Overall, this Special Issue aims at discussing, on the basis of experiences and case studies, the use and consideration of science in existing EU environmental policies and those in the pipeline; additional non-science factors that play a role in policy making; and tools to evaluate the quality of regulations. We are perfectly aware that we did not cover all issues that deserve attention. But in combining the view from different stakeholder scientists, it is our express hope that this Special Issue of Regulatory Toxicology and Pharmacology will foster further discussion and debate among scientists. Encouraged by the lively debates that the presentations created at the SETAC Special Symposia 'Science and Politics' in the last three years, we are confident that this will happen.

\section{Acknowledgments}

We thank Ruth Knowles from the Weinberg Group and Jamie Wardman from the Centre of Risk Management of King's College of London for their help in organising this Special Topics Issue of Regulatory Toxicology and Pharmacology. We are also grateful to the various reviewers for their review of the enclosed publications. 


\section{References}

Dietrich, D.R., Hitzfeld, B.C., O'Brien, E., 2005. Toxicology and risk assessment of pharmaceuticals. In: Reemtsma, T. (Ed.), Organic Pollutants in the Water Cycle. Wiley VCH, Weinheim.

EMEA, 2005. DRAFT: Guideline on environmental risk assessment of medicinal products for human use. CPMP/SWP/4447/00draft, 121.

European Commission, 2000. Communication from the commission on the precautionary principle. COM 2001428 Final.

European Policy Centre, 2005. EPC Working Paper $N^{\circ} 17$. Enhancing the role of science in the decision making of the European Union. Brussels.

Lofstedt, R., 2004. Risk Communication and Management in the 21st Century a working paper for the AEI Brookings Joint Centre for Regulatory Studies. Washington DC.

Lofstedt, R.E., Vogel, D., 2001. The changing character of regulation: a comparison of Europe and the United States. Risk Analysis 21, 399406.

Majone, G., Everson, M., 2001. Institutional reform: independent agencies, oversight, coordination and procedural control. In: DeSch utter, O., Lebessis, N., Paterson, J. (Eds.), Governance in the European Union. Office for the Official Publications of the European Communities, Luxembourg, pp. 129168.

O'Brien, M., 2000. Making better environmental decisions: an alternative to risk assessment. MIT Press, Cambridge MA.

Stern, P., Fineberg, H. (Eds.), 1996. Understanding Risk: Informing Decisions in a Democratic Society. National Academic Press, Wash ington DC.

UNEP, 2001. United Nations Environmental Programme. Stockhold Convention on Persistant Organic Pollutants (POPs). Convention Text. Stockholm, Sweden.
Wandall, B., 2004. Values in science and risk assessment. Toxicology Letters 152, 265272.

WTO, 1995. The WTO Agreement on the Application of Sanitary and Phytosanitary Measures (SPS Agreement). World Trade Organization, Geneva, Switzerland.

Thomas Petry

The Weinberg Group LLC, 360 Boulevard du Souverain, box 5

B-1160 Brussels, Belgium

E-mail address: thomas.petry@weinberggroup.com

Ragnar E. Löfstedt

King's Centre for Risk Management

King's College of London, Strand Building

London, WC2R $2 L S$, UK

Daniel R. Dietrich

Environmental Toxicology

University of Konstanz

Universitätsstraße 10

D-78457 Konstanz, Germany 